\title{
On Integrated Sediment Transport Modelling for Flash Events in Mountain Environments
}

\author{
Alessio RADICE, Elisa GIORGETTI, \\ Davide BRAMBILLA, Laura LONGONI, and Monica PAPINI
}

\author{
Politecnico di Milano, Dipartimento I.I.A.R., Milan, Italy \\ e-mails: alessio.radice@polimi.it, elisa.giorgetti@polimi.it, \\ davide.brambilla@polimi.it, laura.longoni@polimi.it, monica.papini@polimi.it
}

\begin{abstract}
Sediment production and transport in mountain basins during shortterm, intense events depend on a variety of processes. Available models typically consider a limited portion of the phenomenological chain, frequently either sediment supply or solid transport along the waterways. On the other hand, proper depiction of on-site processes requires ability to model all the process stages and suitable integration between different models. In this manuscript, an integrated modelling is attempted for small catchments in Italian Alpine foothills. The integrated approach has involved: (i) hydrologic estimation of peak discharge, (ii) evaluation of the volumetric sediment supply into the stream, and (iii) computation of the morphologic evolution of the river bed. The results are discussed focussing on: (i) the feasibility of a joint modelling like the one presented, in the light of all the limitations imposed by the different nature of hillslope-devoted and river-devoted models; and (ii) the sensitivity of the obtained results to some parameters, for an assessment of result reliability.
\end{abstract}

Key words: mountain basins, sediment supply, fluvial sediment transport, morphologic evolution.

\section{INTRODUCTION}

The normal life of sediments in a river basin is first being eroded from the valley slopes by a number of endogenous and exogenous agents and later 
migrating along the catchments. This process has been extensively studied, either with reference to its single phases or globally, due to several implications for land use, managing practices and territorial hazard. For example, in farmland basins the loss of fertile soil represents a shortcoming for agriculture; from the point of view of public safety, sediments eroded in mass may be involved in landslides or debris flows; furthermore, sediment transport in rivers results in morphologic evolution of the river bed, with possible damages to structures or increased water levels in case of degradation or aggradation, respectively.

Among all the different issues, the interest of this manuscript is on the morphologic evolution that can be expected in a river course as a consequence of short-duration, intense events and related sediment supply. Proper modelling of a complete process sequence requires multi-disciplinary competences, at least in the fields of geology, geotechnics and river hydraulics. Conceptually, it can be assumed that sediment supply represents a boundary condition for the transport along water courses. In addition, it should be borne in mind that phenomena related with the above picture are highly complex and interacting over a variety of spatial and temporal scales, which further makes the satisfactory modelling a challenge for the time being.

In the literature on production of sediments by river basins, a distinction is frequently made between off-site and on-site processes (see e.g., the review by De Vente and Poesen 2005), with the former being those taking place downstream of the chosen investigation domain, and the latter being those occurring within the basin (or sub-basin) under consideration. Processes of the first type are, for example, those related with reservoir silting (e.g., Chikita 1990, Lajczak 1996, De Cesare et al. 2001, Elçi et al. 2007); the on-site processes are, for example, those related with local morphology of slopes and water courses (e.g., Owczarek 2008). Based on the intent declared above, this manuscript focuses on processes of the second type. Therefore, tout-court application of models furnishing the sediment at a basin outlet, even if possibly time-distributed (e.g., Arnold et al. 1995, Rickenmann 1997, Jain et al. 2005, Wang et al. 2009) would be unacceptable for the purpose. By contrast, a coupling between models for sediment production and other ones (like, e.g., those of Papanicolaou et al. 2004 or Chiari et al. 2010) for detailed representation of sediment transport and consequent morphologic evolution of the river bed is necessary.

In this paper an attempt is presented to set up an integrated modelling of sediment transport along valley slopes and water courses. The case-study used as a support to the modelling is a small basin in the Italian Alpine foothills. The obtained results are discussed with particular attention to the following issues: (i) modelling strategies, (ii) interfaces between the models for sediment production and those for sediment transport, (iii) possibility to 
choose/select a proper process chain to be modelled, and (iv) possibility to generalize principles and methods to other sites, obviously accounting for specific features of any basin.

\section{THE CASE-STUDY: ROSSIGA VALLEY}

The Rossiga Valley is located in northern Italy and is part of Valsassina within the Alpine foothills. The basin (see Fig. 1) covers an area of $3.6 \mathrm{~km}^{2}$, with maximum and minimum altitudes around 1800 and $500 \mathrm{~m}$ a.s.l., respectively. The mean annual rainfall is around $1700 \mathrm{~mm} / \mathrm{year}$. The mainstem has a length of $3.7 \mathrm{~km}$ and the reach considered here spans the last $1.2 \mathrm{~km}$ before the Rossiga river flowing into the Pioverna. The latter is the main river in Valsassina and a tributary of the Como lake. The mean channel slope in the study reach is $13 \%$.

From a geological point of view, the Valsassina lies at the edge of the so-called Orobic anticline. The rock substrate of the valley is compound of gneiss, verrucan, quartz-diorite, sandstone, and marlstone. The cover is made of alluvial, colluvial, and glacial deposits, as well as landslide material. The most evident surface instabilities are some landslides located in the lowest part of the basin, on the right side of the Rossiga river (Fig. 1). Characteristics of the landslides are as follows: area ranging from 2500 to $23000 \mathrm{~m}^{2}$, difference in elevation from lowest to highest from 90 to $235 \mathrm{~m}$, and estimated volume from 5000 to $130000 \mathrm{~m}^{3}$.

The documentation made available by Regione Lombardia shows that geologic instability of this basin is mostly related with shallow landslides

(a)

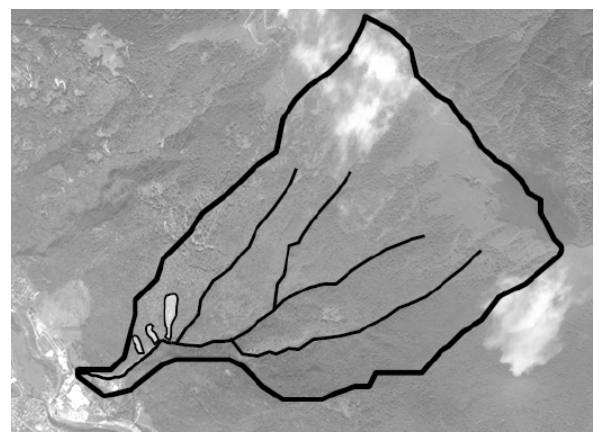

(b)

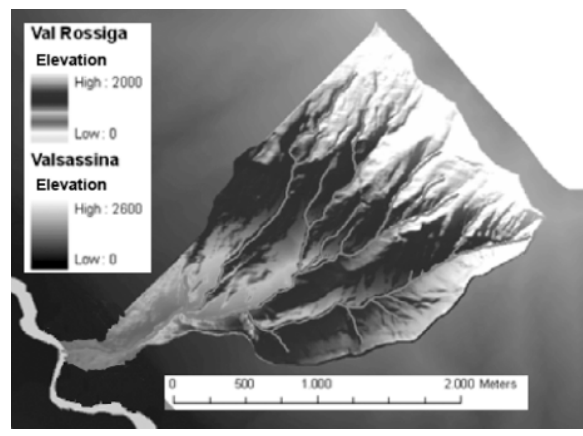

Fig. 1: (a) Google-Earth view of the hydrographic basin (North upwards), with catchments boundary and main water courses highlighted. The lighter areas indicate the major landslides in the downstream part of the basin. In the lower-left corner of the picture, part of the town of Cortenova and the Pioverna river flowing N-E to the lake of Como can be seen; (b) shaded-relief DEM with indication of elevation and distance scales. 
and debris flows, which may make large sediment volumes available during extreme hydrologic events. Indeed, several flood events have been recorded $(1801,1843,1903,1944,1951,1965,1996$, and 2002), in many of which a very intense sediment transport has been documented in the Rossiga river (events of 1801, 1903, and 1996), in some cases with significant aggradation of the river bed leading to flooding (1951). A recent disastrous event occurred in November 2002, when intense and prolonged rainfall triggered motion of the shallow landslides; the latter yielded a sediment volume later estimated as being around $100000-200000 \mathrm{~m}^{3}$. This material originated a debris flow in the Rossiga river, whose left bank was overtopped.

\section{INTEGRATED MODELLING}

\subsection{Objectives and concept}

The objective pursued in this manuscript is to model the process chain leading to morphologic evolution of the river bed due to intense bed-load sediment transport during high-flow events with considerable sediment supply. In the conceptual framework used here (see Section 4 for a discussion of this and other issues), the river bed must remain an identifiable entity; therefore, the processes under investigation are not comparable with that of the 2002 event, which would require modelling of a debris flow with specific rheology of the water and sediment mixture.

A key choice is preliminarily made for the scale of modelling. In natural processes, sediment supply and transport co-exist over a variety of spatial and temporal scales. Support scales for modelling are, instead, frequently separated. The morphologic evolution of a river is typically an on-site process, that is, spatial resolution much finer than the basin scale is necessary; on the other hand, such a resolution is not allowed for by sediment supply models. Similarly, the estimation of a temporal distribution for sediment supply is quite hard to be achieved due to extensive data requirements for the entire basin and thus integral volumes of supply are frequently computed; yet, on the other hand, unsteady river modelling is necessary. The gap between natural complexity and model feasibility makes a conceptual separation necessary. In this work, it will be assumed that a "break-point" (BP henceforth) can be chosen within the basin. The effect of this point will be twofold: (i) from the spatial point of view, the sediment supply will be modelled upstream of BP using the entire upstream portion of the basin as spatial scale, while downstream the river flow will be modelled with the typical resolution of cross sections; and (ii) from the temporal point of view, a time evolution of sediment supply will be artificially generated from the integral volumes estimated. 
For some stages of the chain, very simple models will be used. Indeed, the intent of the work is to seek an integration of models; complexity and sophistication of each of them shall be the minimum acceptable one for meaningful results to be obtained.

\subsection{Hydrologic modelling}

The hydrologic analysis refers to the sub-basin upstream of BP according to the conceptual framework mentioned above. A flow hydrograph is sought to be later used as boundary conditions for modelling on-site processes in the river reach flowing through the downstream part of the basin.

The peak discharge for the modelled scenario has been computed based on the rainfall for several return periods. A very simple hydrologic model has been used, consistently with the goal stated above. It has been chosen to apply a linear rainfall-runoff model assuming space-uniform and timeconstant rainfall intensity. As a result, the time-discharge curve is linear and reaches the peak discharge, $Q_{p}$, at a time equal to the time of concentration of the basin, $t_{c}$. The latter has been computed using the formula (1) by Giandotti (1934), that is of typical use in Italy for basins similar to that considered here:

$$
t_{c}=\frac{4 \sqrt{A}+1.5 L}{0.8 \sqrt{z_{m}}} .
$$

Symbols in Eq. (1) are as follows: $A$ is the basin area in $\mathrm{km}^{2}, L$ is the length of major river reach in $\mathrm{km}$, and $z_{m}$ the mean ground elevation above the downstream section. The rainfall depth, $h_{r}$, has been computed by the Intensity-Duration-Frequency curves (Eq. (2)) using values of the parameters $a$ and $n$ provided by Regione Lombardia. The uniform rainfall intensity, $i_{r}$, has been computed by Eq. (3) and the resulting peak discharge has been computed using the rational method (Eq. (4)) and assuming a runoff coefficient $\varphi=0.3$, given the high permeability of the soil. The obtained results are listed in Table 1.

Table 1

Hydrologic analysis. The $T_{r}$ is the return period

\begin{tabular}{|c|c|c|c|}
\hline Parameter & $T_{r}=20$ years & $T_{r}=100$ years & $T_{r}=200$ years \\
\hline$a\left[\mathrm{~mm} / \mathrm{h}^{n}\right]$ & 53.6 & 69.4 & 76.2 \\
$n$ & 0.34 & 0.33 & 0.32 \\
$h_{r}[\mathrm{~mm}]$ & 46.3 & 60.2 & 66.1 \\
$Q_{p}\left[\mathrm{~m}^{3} / \mathrm{s}\right]$ & 21.4 & 27.8 & 30.6 \\
\hline
\end{tabular}




$$
\begin{gathered}
h_{r}=a t_{c}^{n}, \\
i_{r}=\frac{h_{r}}{t_{c}}, \\
Q_{p}=\varphi i_{r} A .
\end{gathered}
$$

\subsection{Sediment supply}

The analysis of sediment supply refers, in the same way as the hydrologic one, to the sub-basin upstream of BP. In this case, a sediment volume shall be obtained to properly feed the following hydraulic computation of the morphologic evolution of the river bed downstream of BP.

Multiple sources of sediments are typically present in natural basins. In this work, different formulations have been used. First, the MUSLE model (Williams and Berndt 1975) has been applied to evaluate the contribution to total supply by soil erosion. The MUSLE model is represented by

$$
Y_{s}=R_{d} \times K \times L S \times C \times P,
$$

where $R_{d}$ is a runoff factor function of peak discharge and volume of flood, $K$ is the soil erodibility, $L S$ is a factor depending on slope length and gradient, and $C$ and $P$ are factors depending on soil cover and management and on conservation practice, respectively. The obtained sediment volumes are very small (226 and $338 \mathrm{~m}^{3}$ for return periods of 20 and 200 years, respectively). It may be thus argued that soil erosion represents a negligible fraction of the total sediment supply (as found by the authors also in other basins; see e.g., Brambilla et al. 2011). Application of Eq. (5) furnishes a total volume with no information on the temporal evolution of sediment supply. In the past, several approaches have appeared in the literature based on basin subdivision into small cells; such models use equations similar to the USLE one for sediment production and model sediment routing based on the concept of mass continuity (e.g., Bemporad et al. 1997, Jain et al. 2005, Krysanova et al. 2005, Van Rompaey et al. 2005, Warren et al. 2005, Wang et al. 2009). In this way, more detailed information about the spatial distribution and the temporal dynamics of sediment supply may be provided. However, for basins similar to that used here the sediment volume from soil erosion is likely a negligible fraction of the total one and this suggested to neglect it in further analyses.

Given the characteristics of the Rossiga Valley, a relevant sediment supply is likely to come from landslides and local debris flows. Estimation of the sediment volumes that can be supplied to the downstream part of the ba$\sin$ is not straightforward. In this analysis, some literature formulae have been used aimed at furnishing the magnitude of the sediment supply and enabling possible presence of landslides and debris flows to be accounted for 
(Hampel 1977, Takei 1984, Rickenmann and Zimmermann 1993, Rickenmann 1995, D'Agostino et al. 1996, Marchi and Tecca 1996, Ceriani et al. 2000). Some of these equations have been developed specifically for Alpine environments like that considered here. Parameters typically included in such equations are the basin area, length and slope; sometimes, qualitative indexes are included to account for specific size and distribution of landslides, as well as relevance of debris flows compared with intense bed load in the hydrographic network. None of the formulae found in the literature includes a dependence on the return period of the event scenario related with the estimation. Values obtained for the present basin are listed in Table 2, where a scatter of one order of magnitude is found. The high differences resulting from the use of different equations may be due to simplicity of all these approaches. It is remarkable to note that the formula by Marchi and Tecca (1996), which is simply of type

$$
\text { supply }_{\text {sediment }}=\text { const } \times \text { area }_{\text {basin }},
$$

furnishes a reasonable value within the range of the other ones.

Table 2

Estimation of magnitude of sediment supply by several literature formulae

\begin{tabular}{|l|c|l|c|}
\hline \multicolumn{1}{|c|}{ Formula } & $\begin{array}{c}\text { Magnitude } \\
{\left[\mathrm{m}^{3}\right]}\end{array}$ & \multicolumn{1}{|c|}{ Formula } & $\begin{array}{c}\text { Magnitude } \\
{\left[\mathrm{m}^{3}\right]}\end{array}$ \\
\hline Hampel (1977) & 106500 & D'Agostino et al. (1996) & 23776 \\
Takei (1984) & 29500 & Marchi and Tecca (1996) & 35600 \\
Rickenmann and & & Ceriani et al. (2000) & 102300 \\
Zimmermann (1993) & 43900 & & \\
Rickenmann (1995) & 15875 & & \\
\hline
\end{tabular}

\subsection{Morphologic evolution of the river bed}

The morphologic evolution of the river bed is modelled downstream of BP considering no further water and sediment supply along the river course. The modelling approach used is the classical system of the Saint Venant and Exner equations for the liquid and solid phase, respectively. As well-known, a fourth equation is necessary to compute the transport capacity of the flow given the local hydrodynamic conditions. In this work, the equation by Meyer-Peter and Müller (1948) has been used. Upstream boundary conditions are necessary in terms of flow hydrograph and sediment supply (see Fig. 4a). For the former, a triangular hydrograph with peak discharge equal to $30.6 \mathrm{~m}^{3} / \mathrm{s}$ and duration equal to twice the time of concentration of the ba- 
sin has been used, as given by the hydrologic modeling. For the latter, a temporal evolution of sediment supply is necessary, that is not given by the evaluations applied. Therefore, for a first model it has been chosen to create a time-supply curve with yield rate proportional to squared flow rate and a total volume of supplied sediments of $15000 \mathrm{~m}^{3}$. Based on observation of the material deposited in the river bed, a characteristic sediment size $d=$ $0.2 \mathrm{~m}$ has been assumed for both the river bed and the supplied material. The computations have been carried out using the software Basement developed at ETH Zürich (Fäh et al. 2010, see also http://www.basement.ethz.ch). The solver applies the finite-volume method for spatial discretization and the Euler explicit scheme for the temporal one. Flow resistance is modelled using the Manning-Chézy approach. For the sake of simplicity, a uniform Manning coefficient of $0.04 \mathrm{~s} / \mathrm{m}^{1 / 3}$ has been used in all the sections.

The results of the described model are depicted in Fig. 2. The final profile of the river bed (Fig. 2a) shows large aggradation in the portions of the reach with local decrease of bed slope (that is in general accompanied by increase in channel width). For example, about $5 \mathrm{~m}$ of aggradation have been obtained at around $150 \mathrm{~m}$ from BP (see the zoom in Fig. 2c). The general dynamics of the sediment wave supplied upstream can be summarized as a longitudinal dispersion of the sediment volume. By contrast, translational mechanisms are not evident observing the temporal evolution of the river bed (not shown here). This result is consistent with typical descriptions of sediment transport in real- and laboratory-scale studies (e.g., Madej and Ozaki 1996, Lisle et al. 2001, Sklar et al. 2009). Maximum aggradation heights are around some metres, inducing significant rise of the maximum water elevations compared with a condition of fixed bed (Fig. 2b). In this case there should be no risk of flooding thanks to high bank elevation, but in many events sediment transport processes and consequent morphologic evolution (aggradation) have induced flooding at other sites in the Alpine region (see e.g., Klaassen 1997 or Jaeggi 2008).

The temporal evolution of solid discharge at each section can be integrated to obtain the total volume transported at the same location. The longitudinal profile of the volume transported during the event is shown in Fig. 3. Now, let $W_{i}$ and $W_{i-1}$ be the sediment volumes transported at a certain section and at that immediately upstream, respectively. The difference $W_{i-1}-W_{i}$ (delta $W$ hereafter) is used to quantify the volume available for aggradation along the reach separating the two sections. The longitudinal profile of this difference is shown in Fig. 3, highlighting in a different way the reaches of the river with a tendency to aggradation. Finally, the differences of transported volume can be cumulated along the reach to show the general tendency of the latter; also this profile (quantity indicated as cum_delta $W$ ) is presented in Fig. 3. It is evident from both the transported volume and the 


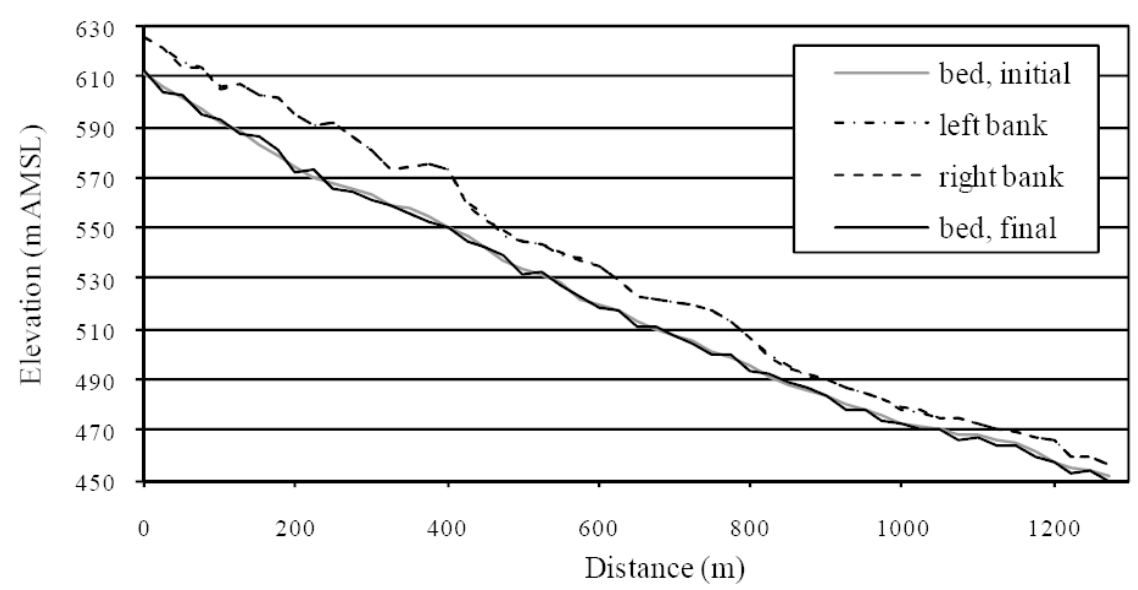

(a)

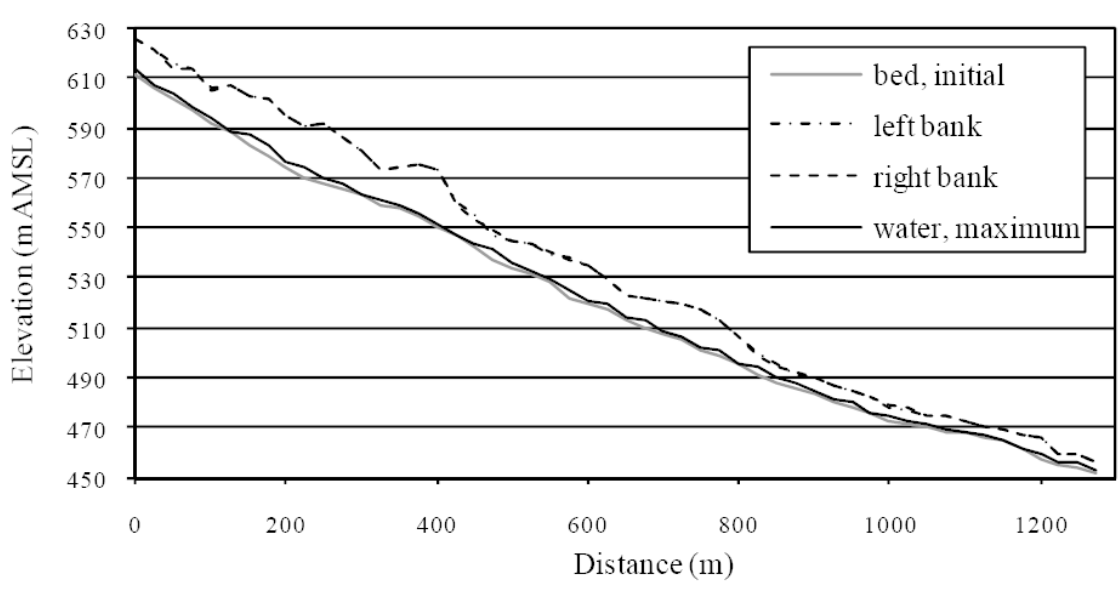

(b)

(c)

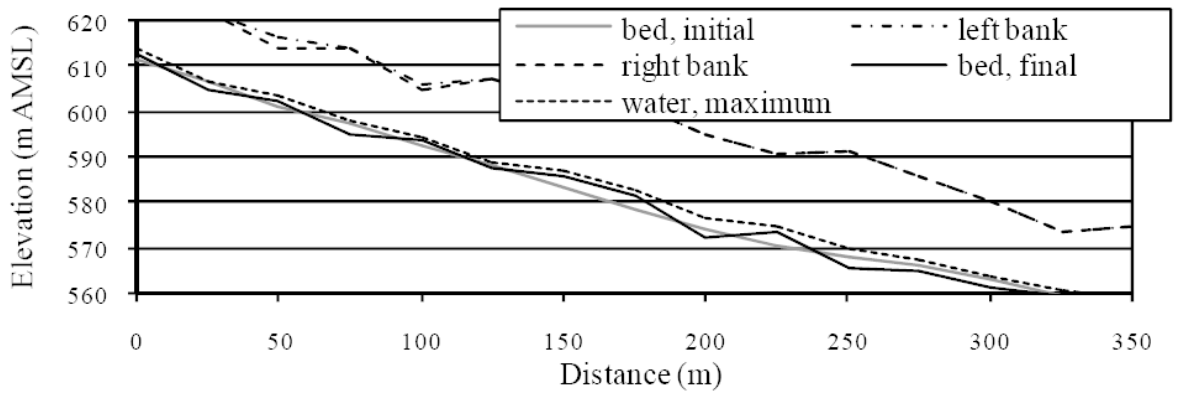

Fig. 2. Results for model 01 of Table 3: (a) profile of the river bed at the beginning and at the end of the modelled event, (b) maximum water elevation during the event, and (c) zoomed picture of the upstream portion $(350 \mathrm{~m})$ of the reach. 


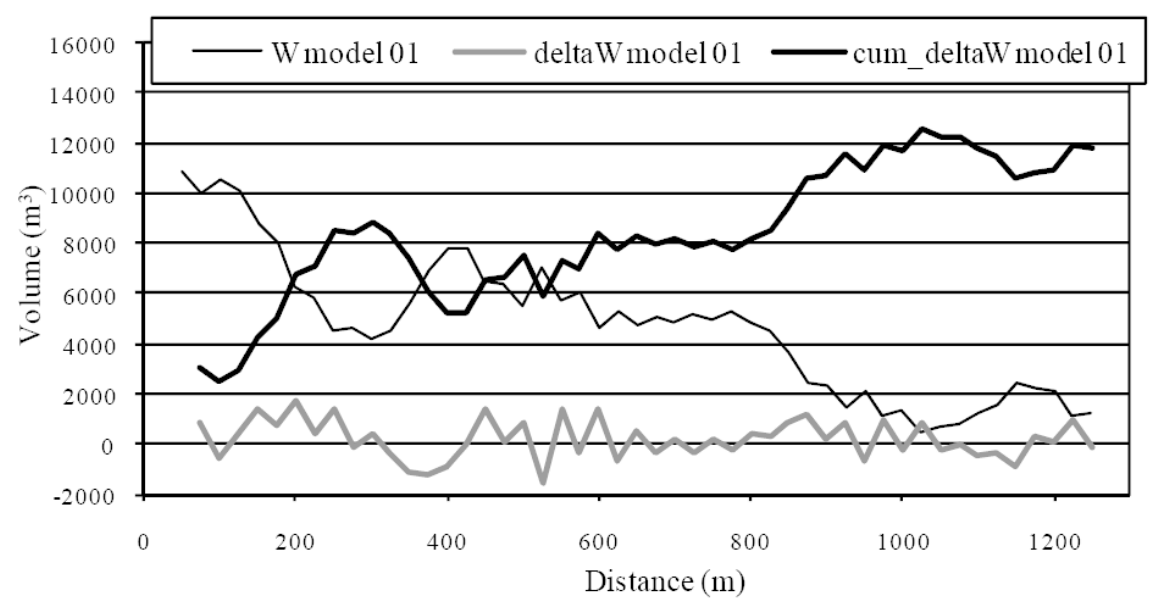

Fig. 3. Results for model 01 of Table 3, longitudinal profiles of sediment volumes: $W$ is the total transported volume at each cross-section, delta $W=W_{i-1}-W_{i}$ represents the unbalance between the volume transported at a certain section ( $i$-th) and that transported at that immediately upstream (labelled $i-1$ ), and cum_delta $W$ is the progressive accumulation of the above differences along the reach. See text for further details.

cumulative aggradation volume that a small portion of the sediment supply is conveyed to the downstream section of the reach within the event duration, whilst almost all the supplied volume is deposited throughout the length of the stream.

The modelling performed has led to reasonable results, but the latter may be highly uncertain given the assumptions made choosing the boundary conditions and the parameters for the computation. Therefore, a sensitivity analysis has been made in order to check variability of the results with the choices left to the modeller. Characteristics of the devised scenarios are provided in Table 3, where model 01 in the table is that already discussed above. Reasons for the changes are here briefly discussed. The basic idea is that the parameters not given, or given with uncertainty, by the supply models have to be changed. The total sediment supply is not ascertained given the scatter of values in Table 2 . In principle, any supply value from 15000 to $110000 \mathrm{~m}^{3}$ may be supported by the evaluations made. It has been however decided to limit the supply to $55000 \mathrm{~m}^{3}$ because larger values would imply a sediment volume larger than the water's one (see Fig. 4). Even the largest supply used here would probably induce a hyper-concentrated flow and is thus probably too large for the scope of the present analysis. Indeed, since the declared intent was to avoid hyper-concentrated flows, volumes equal to the largest considered here and larger than the latter would be conceptually 
Table 3

Scenarios for analysis of morphologic evolution of the river bed.

For model 04 the delay of the sediment supply has been arbitrarily chosen

\begin{tabular}{|c|c|c|c|c|}
\hline Model & $\begin{array}{c}Q_{p} \\
{\left[\mathrm{~m}^{3} / \mathrm{s}\right]}\end{array}$ & $\begin{array}{c}\text { Duration } \\
{[\mathrm{h}]}\end{array}$ & $\begin{array}{c}d_{50} \\
{[\mathrm{~m}]}\end{array}$ & $\begin{array}{c}\text { Yield } \\
{\left[\mathrm{m}^{3}\right]}\end{array}$ \\
\hline 01 & 30.6 & 4.1 & 0.2 & 15000 \\
02 & 30.6 & 4.1 & 0.2 & 35000 \\
03 & 30.6 & 4.1 & 0.2 & 55000 \\
04 & 30.6 & 4.1 & 0.2 & 35000 , delayed \\
05 & 30.6 & 4.1 & 0.1 & 35000 \\
06 & 30.6 & 4.1 & 0.4 & 35000 \\
\hline
\end{tabular}

unsound. This volume has been however used to check the effect of a limiting condition for model applicability. It has also been mentioned above that supply models do not furnish the temporal evolution of the sediment volume. Therefore, model 04 was created based on a scenario where the sediment supply is not simultaneous with the flow hydrograph, but is delayed (see again Fig. 3). The representative sediment size has been changed since no supply model provides its value.

Flow and sediment rates in Fig. 4 show that in none of the models performed the upstream sections of the river are able to transport the sediment supplied as boundary condition (that is, the reach is transport-limited according to typical definitions). In addition, the integral of the sediment rate curve is similar for all models with synchronous sediment supply except model 06 with larger sediments. For model 04 the sediment supply begins to rise when the peak flow is taking place; therefore, the sediment transport capacity is initially able to follow entirely the amount of supplied sediments, while for larger times the transport capacity is again too low for all the sediments to be conveyed downstream. In all the cases the sediment conveyed out of the reach is just a small fraction of the supply.

The final configuration of the bed profile is not much sensitive to the model used, as well as the maximum water elevation computed. The above results are not shown here but the sediment volumes are presented in Fig. 5. The analysis of $W$ (Fig. 5a) shows inverse relationship between sediment size and sediment transport. For $d=0.4 \mathrm{~m}$, in some sections there is no sediment transport because the shear stress does not exceed the threshold for incipient particle motion. The curve of cumulative aggradation volume (Fig. 5b) does not show particular differences as long as $d \leq 0.2 \mathrm{~m}$ is considered, while differences emerge again for $d=0.4 \mathrm{~m}$ : in the first case, around $75 \%$ of the input sediment is deposited within the first $300 \mathrm{~m}$, whilst in the second one the percentage increases to $85 \%$. Such a behaviour is obviously 
(a)

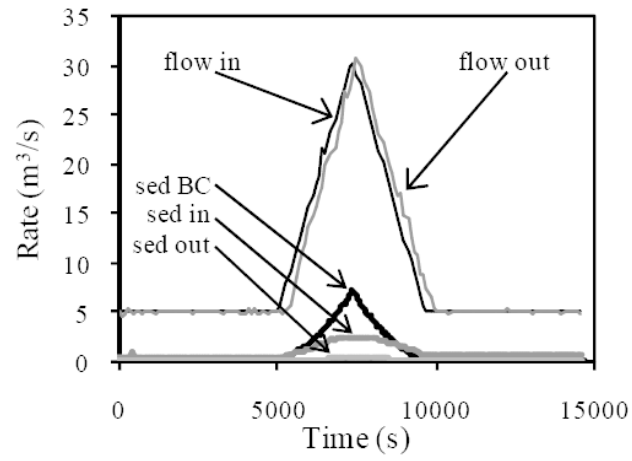

(c)

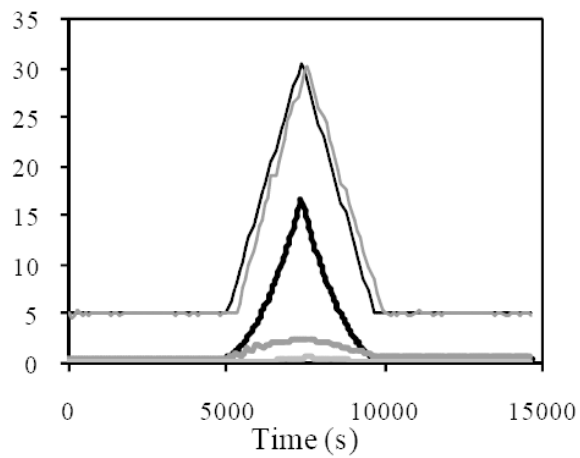

(d)
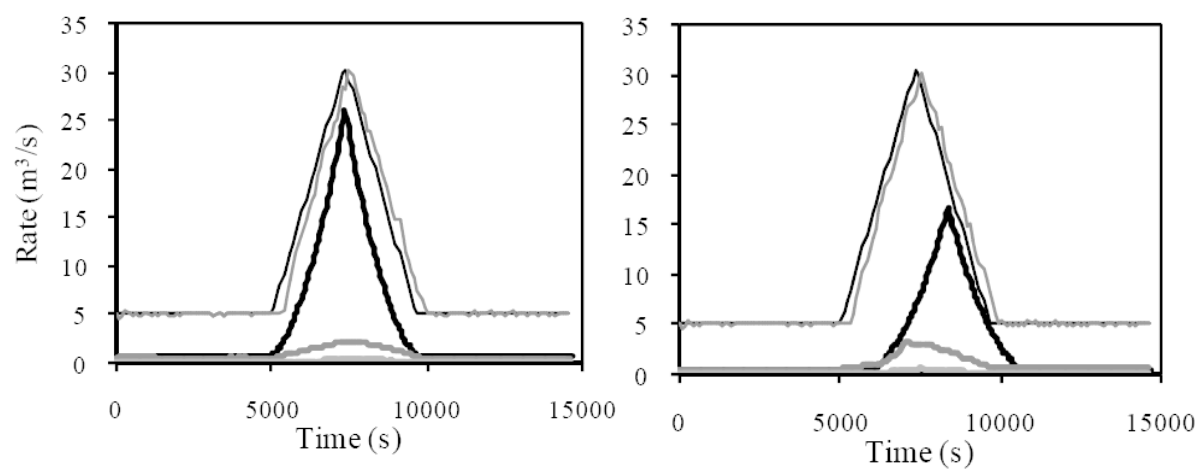

(e)

(f)
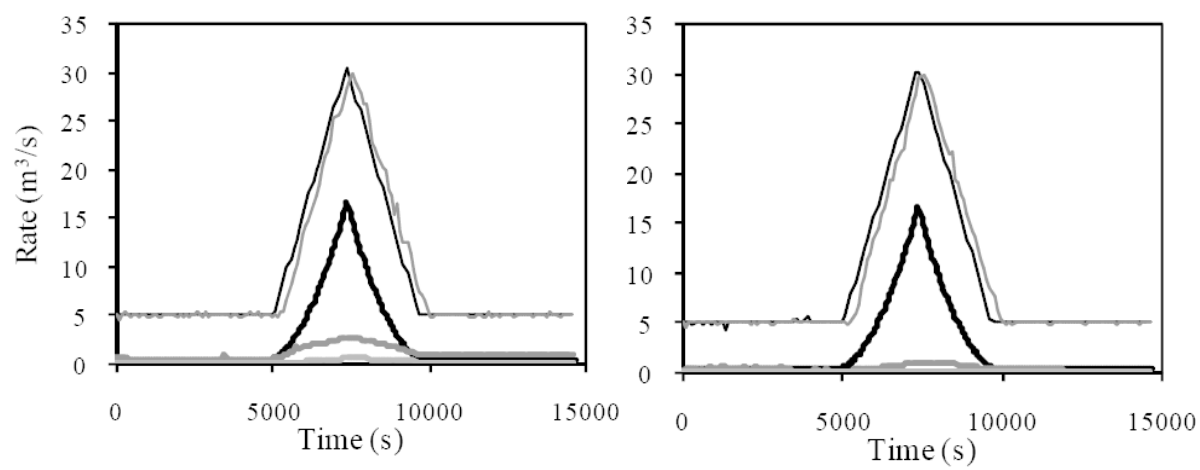

Fig. 4. Hydrographs and sediment transport rates at river inlet and outlet for the models in Table 3. Letters from (a) to (f) correspond to models from 01 to 06 . Legend in first plot holds also for the others. Code "sed BC" identifies the time-supply curve input as upstream boundary condition. 


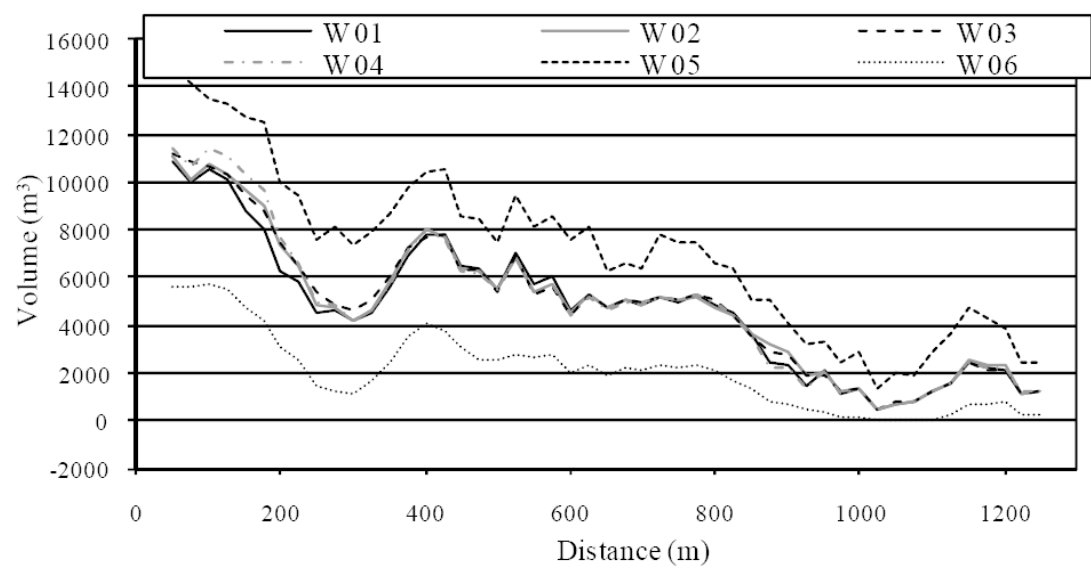

(a)

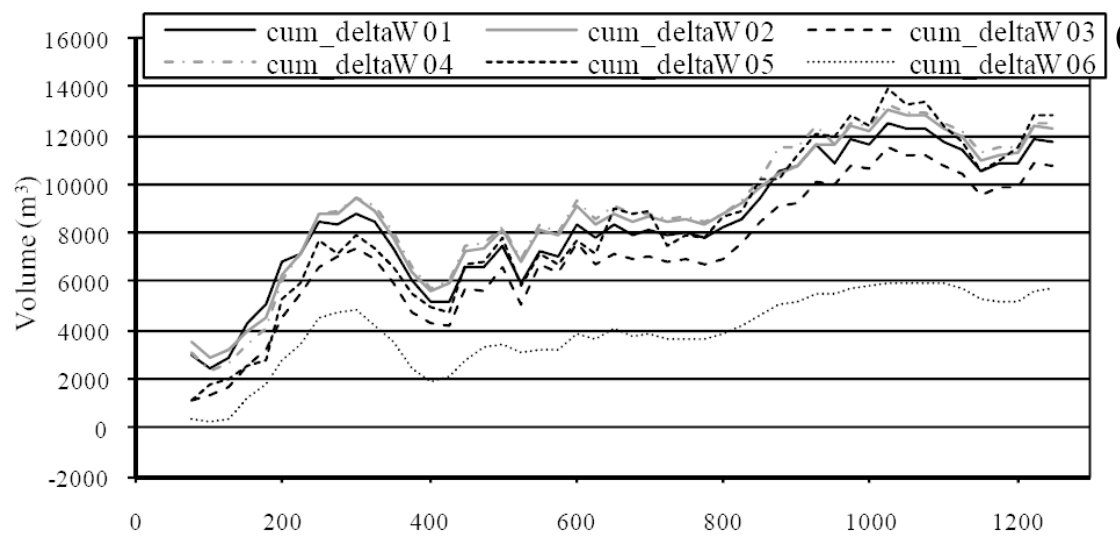

(b)

Distance (m)

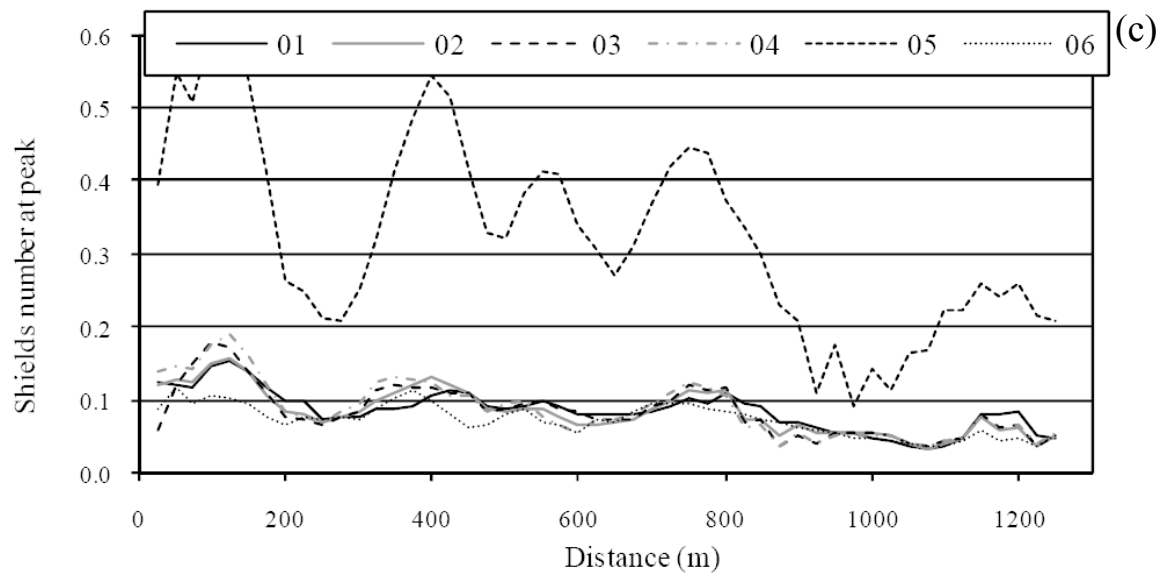

Fig. 5. Results of the sensitivity analysis: (a) transported volume $W$, (b) cum_delta $W$, and (c) Shields number at peak flow for the models in Table 3. 
related with the bed shear stress, presented in Fig. 5c through the Shields (1936) number at the time of peak flow. Models from 01 to 04 can be used to argue a relative non-dependence of the final aggradation pattern on the sediment volume supplied upstream. This finding is in agreement with some literature description of the process (see e.g., Reid et al. 2007), where the initial geometry of the reach (local slope, channel width, confinement) may prevail on the upstream supply for short evolution times.

\section{DISCUSSION}

As seen in the above sections, the key driving idea of the proposed integrated approach has been the separation between the processes of sediment supply and sediment transport. The phenomena have been separated in space (through introduction of a break-point, BP) and an artificial time development of sediment supply has been used. In this section, advantages and shortcomings of the modelling approach used are discussed in light of the arbitrary modelling choices required and of uncertainty of final results compared with engineering evaluations. Modelling strategies are discussed first, following the sequence in which they appear in computations.

Sediment load in mountain environments may involve a variety of processes. Most typical modes of transport of coarse sediments are bed load and debris flow, as discussed, for example, by Rickenmann and Koschni (2010). Any stream may be more prone to one or the other process, typically depending on basin morphology. Typically, steeper reaches are more likely for onset of debris flows, and the latter generally involve much larger sediment volumes (e.g., Mao et al. 2009). In this work, the sediment transport in the study reach has been assumed to take place as bed load, due to the slope of the study reach. On the other hand, it has been assumed that debris flow might locally occur on the valley slopes. Indeed, the estimation of the sediment supply into the river has taken advantage of formulae developed for debris-flow prone basins. In summary, the modelling strategy is extremely dependent on the phenomenological chain that the modeller chooses, and whose suitability has to be ascertained.

In hydrologic modelling, a typical assumption has been followed, according to which the critical rainfall event for a basin is that having a duration equal to the time of concentration of the catchments. Indeed, this choice maximizes the peak discharge at the downstream section and thus represents the worst condition to evaluate the freeboard left at the banks. By contrast, when mobile-bed processes are considered, validity of this hypothesis is not ascertained. For example, several literature works have introduced the concept that the sediment volume put into movement depend on the peak discharge but also on the total volume of the flood event (that, in turn, is 
obviously a function of event duration). Similar considerations are mentioned in Jaeggi (2008) and Lenzi et al. (2004), and are implemented in the experimental formulae by Rickenmann (1997). In addition, proposals in this sense have been made also with reference to models of soil erosion and routing (e.g., Wang et al. 2009).

In the approach used here, the very simple MUSLE equation has been used to evaluate soil erosion. Limitations of such equation are that local deposition is not explicitly taken into account, as well as that it has been applied here in a context that is different from that for which it has been developed (farmland in the U.S.). The models used for the evaluation of the sediment supply in basins with significant instabilities, such as landslides and debris flows, have highlighted a very large scatter among the different values obtained. It is not clear if the contributions due to soil erosion and the second one should be added or, vice versa, the second one should ideally include the first. It is however noted here that, for the basin considered, a high separation between the volumes related with the two approaches has allowed to neglect the first one. In any case, a common flaw of the formulae for sediment supply is that no information is provided about the temporal dynamics of the sediment production and the grain size distribution of the material. This poses serious limitations to the following model of the morphologic evolution of the river bed, since the above pieces of information are necessary as boundary conditions and, in the absence of any indication, the modeller has to make arbitrary (though as reasonable as possible) assumptions, as mentioned also by Wright et al. (2010).

The basin studied here did not suggest to consider other types of sediment sources. If the catchments had presented any peculiarity leading to relevance of another source (for example, fault rocks, erosion by karstification, and possibly others) this should have been considered apart and implemented along with the other ones in some non-straightforward way.

The granulometric distribution of the material within the river bed and of the supplied one are key factors for the models of sediment transport. If a monogranular model is applied (like here) the sizes of the river sediment and of the supply are the same, which may not be the typical case in reality. A survey of the material deposited in the river bed may be used to assess some representative dimension. However, the results presented above highlighted that the final result is not much dependent on the sediment size as long as significant transport is possible (only model 06 characterized by lowest values of the Shields number presented appreciable differences from the other ones; see Fig. 5b). The above finding is known as the equal mobility of sediment fractions (e.g., Rickenmann 1997, Lenzi et al. 1999, Mao and Lenzi 2007) and reduces the effect of uncertainty on sediment size. On the other hand, a number of different processes take place in a mountain river 
due to non-uniform granulometric distribution. First, the incipient particle motion is altered (e.g., Wilcock 1998, Lenzi et al. 2006, Garcia et al. 2007, Mao et al. 2008), mostly due to hiding and armouring effect. Second, the sediment transport rates for a given water discharge may be different if the sediments are uniform or not (e.g., Cohen et al. 2010). Finally, non-uniform size of sediments leads to downstream fining (e.g., Paola et al. 1992, Ferguson et al. 1996, Seal et al. 1997, Gomez et al. 2001). It is however likely that such process should not be particularly relevant in the short river reach modelled here.

Additional uncertainty for the hydraulic modelling arises from the bedload formula used (as discussed, e.g., by Gomez and Church (1989), Rickenmann (2001), and Martin (2003)). Rickenmann and Koschni (2010), for example, found that the Meyer-Peter and Müller (1948) equation for bed load was valid for channel slopes lower than 5\%, while for larger slopes the formula overestimated the sediment transport rate. On the other hand, for example, Mandelli et al. (2009) performed a sensitivity analysis comparing the results of the Meyer-Peter and Müller's (1948) and Rickenmann's (2001) equations, finding a disagreement comparable with other typical modelling uncertainties. Surely proper calibration of an ad hoc sediment transport formula for any case under investigation may significantly increase result reliability.

The computation of bed-load sediment transport suffers also from the choice of proper threshold value for the Shields number. On the one hand, it may be argued that the effect of such a value is analogous to that of the representative sediment size, since the two parameters act similarly (in other words, using higher critical Shields number or increasing the particle size correspond to different concepts but lead to similar numerical results). Here, the effect of the particle size has been found relatively small. On the other hand, the above-mentioned issues related with the incipient particle motion in the presence of granulometric variability may impact the results.

The morphologic evolution of the stream has been carried out hypothesizing transport-limited conditions. Montgomery and Buffington (1997) presented a classification of river morphologies based on the associated sediment transport processes; stream geometry and transport conditions were related to each other through the properties of flow resistance. Even though a sharp distinction between the categories was not proposed, the river morphology was found to be mostly related with slope and drained area. The river under consideration here would likely result within the step-pool category (examples of specific studies of this morphology and associated processes are provided by Lenzi et al. 2004, Milzow et al. 2006, Turowski et al. 2009, Wilcox et al. 2011). On one hand, according to Montgomery and Buffington (1997) this particular geometry is developed by the river in supply- 
limited conditions, because the steps maximize river resistance and reduce the skin friction responsible for sediment transport. On the other hand, the formative processes are related with large temporal scales, while the same authors stated that during short and strong events the shape of a river may change. The scenario considered here has involved a peak flow with very large supply from the valleys. In these conditions, Lenzi (2001) proposed that the step-pool structure may be destroyed by pool filling.

A last consideration to be made here is that the sediment transport in the river has been considered only in terms of bed load, without accounting for sediment suspension. The latter is highly variable and hardly quantifiable (see e.g., the striking scatter of field data provided by Turowski et al. 2010). Suspended sediment transport is likely to represent the major mode of solid mass transfer and have prevailing role in erosion/deposition processes for large rivers (e.g., Wright et al. 2010 have analyzed morphology of the Missouri river considering an Exner approach where sediment fluxes were in suspension only). As the dimension of the system decreases, the relative contribution of sediment suspension is expected to decrease accordingly (Turowski et al. 2010), even though such assumption is not fully ascertained (as shown, e.g., by the results of Lenzi and Marchi 2000 and Lenzi et al. 2003).

All the modelling uncertainties and flaws highlighted here are important limitations that suggest to consider with care the results of models. On the other hand, the final result (that is, the longitudinal profile of the river bed after the event) has been found to be relatively stable and not much dependent on the boundary conditions. Apart from the reasonable need to validate the modelling results against field data (such a validation has not been possible here since the basin is not monitored) it seems that the uncertainty of the final result is not incompatible with engineering evaluations, at least for short-term events like those investigated here. Of course, much further research is needed in order to progressively reduce the modelling limitations highlighted.

\section{CONCLUSIONS}

Numerous implications for land use, managing practices and flood hazard stimulate ongoing study of sediment mass transfer in river basins. In the general context of flood hazard and vulnerability, the aim of this manuscript has been modelling the morphologic evolution expectable for a river bed as a consequence of short-duration, intense events and related sediment supply. Using a basin in the Italian Alpine foothills as case-study, an attempt has been made to devise an integrated modelling of sediment transport on valley slopes and within the main water course. 
The integrated modelling has included: hydrologic rainfall-runoff transformation, supply estimation and computation of the morphologic evolution of the river bed. For all these parts, models as simple as possible have been used, the intent being to seek an integration of models rather than sophistication of each of them. A key concept of the modelling approach has been spatial separation between supply and transport through a break-point to be chosen within the catchments.

The major flaws of the modelling steps have been discussed. Since most of the models have not been developed aiming at an integrated use, much further research is needed in order to make the interface between models as homologous as possible. In particular, supply models do not furnish information about the temporal evolution of sediment volumes and about the granulometry of supplied material. On the other hand, it has been possible to get to a solution provided that some inputs to the morphologic model have been properly (and, to some extent, arbitrarily) assumed. For most of the uncertain parameters a sensitivity analysis has been performed, showing that the final result presents a variability compatible with engineering evaluations.

Acknowledgments. The research has been partially supported by Regione Lombardia under the Project RISSME (RIsk by Sediment Sources in Mountain Environments). The Basement developers of VAW, ETH Zürich are gratefully acknowledged for constant support about model use. Stimulating comments and suggestions provided by two anonymous reviewers have enabled significant improvement to be made of the original version of the manuscript.

References

Arnold, J.G., J.R. Wiliams, and D.R. Maidment (1995), Continuous-time water and sediment-routing model for large basins, J. Hydraul. Eng. 121, 2, 171-183, DOI: 10.1061/(ASCE)0733-9429(1995)121:2(171).

Bemporad, G.A., J. Alterach, F.F. Amighetti, M. Peviani, and I. Saccardo (1997), A distributed approach for sediment yield evaluation in Alpine regions, J. Hydrol. 197, 1-4, 370-392, DOI: 10.1016/0022-1694(95)02978-8.

Brambilla, D., L. Longoni, M. Papini, E. Giorgetti, and A. Radice (2011), On analysis of sediment sources towards proper characterization of hydro-geological risk for mountain environments, Int. J. Safety and Security Eng. (in print).

Ceriani, M., G. Crosta, P. Frattini, and S. Quattrini (2000), Evaluation of hydrogeological hazard on alluvial fans, Proc. Int. Symp INTERPRAEVENT 2000, Villach, Austria, Vol. 2, 213-225. 
Chiari, M., K. Friedl, and D. Rickenmann (2010), A one-dimensional bedload transport model for steep slopes, J. Hydraul. Res. 48, 2, 152-160, DOI: 10.1080/ 00221681003704087.

Chikita, K. (1990), Sedimentation by river-induced turbudity currents: field measurements and interpretation, Sedimentology 37, 5, 891-905, DOI: 10.1111/ j.1365-3091.1990.tb01832.x.

Cohen, H., J.B. Laronne, and I. Reid (2010), Simplicity and complexity of bed load response during flash floods in a gravel bed ephemeral river: a 10 year field study, Water Resour. Res. 46, W11542, DOI: 10.1029/2010WR009160.

D’Agostino, V., M. Cerato, and R. Coali (1996), Extreme events of sediment transport in the eastern Trentino torrents, Proc. Int. Symp INTERPRAEVENT 1996, Vol. 1, 377-386.

De Cesare, G., A. Schleiss, and F. Hermann (2001), Impact of turbidity currents on reservoir sedimentation, J. Hydraul. Eng. 127, 1, 6-16, DOI: 10.1061/ (ASCE)0733-9429(2001)127:1(6).

De Vente, J., and J. Poesen (2005), Predicting soil erosion and sediment yield at the basin scale: Scale issues and semi-quantitative models, Earth-Sci. Rev. 71, 1-2, 95-125, DOI: 10.1016/j.earscirev.2005.02.002.

Elçi, S., P.A. Work, and E.J. Hayter (2007), Influence of stratification and shoreline erosion on reservoir sedimentation patterns, J. Hydraul. Eng. 133, 3, 255 266, DOI: 10.1061/(ASCE)0733-9429(2007)133:3(255).

Fäh, R., R. Müller, P. Rousselot, D. Vetsch, C. Volz, L. Vonwiller, R. Veprek, and D. Farshi (2010), Basement reference manual, available at www.basement. ethz.ch.

Ferguson, R., T. Hoey, S. Wathen, and A. Werritty (1996), Field evidence for rapid downstream fining of river gravels through selective transport, Geology 24, 2, 179-182, DOI: 10.1130/0091-7613(1996)024<0179:FEFRDF>2.3.CO;2.

Garcia, C., H. Cohen, I. Reid, A. Rovira, X. Úbeda, and J.B. Laronne (2007), Processes of initiation of motion leading to bedload transport in gravel-bed rivers, Geophys. Res. Lett. 34, L06403, DOI: 10.1029/2006GL028865.

Giandotti, M. (1934), Previsione delle piene e delle magre dei corsi d'acqua, Memorie e studi idrografici, Pubbl. 2 del Servizio Idrografico Italiano 8, 107 (in Italian).

Gomez, B., and M. Church (1989), An assessment of bed load sediment transport formulae for gravel bed rivers, Water Resour. Res. 25, 6, 1161-1186, DOI: 10.1029/WR025i006p01161.

Gomez, B., B.J. Rosser, D.H. Peacock, D.M. Hicks, and J.A. Palmer (2001), Downstream fining in a rapidly aggrading gravel bed river, Water Resour. Res. 37, 6, 1813-1823, DOI: 10.1029/2001WR900007.

Hampel, R. (1977), Geschiebewirtschaft in Wildbächen, Wildbach und Lawinenverbau 41, 1, 3-34 (in German). 
Jaeggi, M. (2008), Some aspects of the sediment transport during the 2005 floods in Switzerland, Ann. Warsaw Univ. of Life Sci. - SGGW, Land Reclam. 39, 33-48, DOI: 10.2478/v10060-008-0003-8.

Jain, M.K., U.C. Kothyari, and K.G. Ranga Raju (2005), GIS based distributed model for soil erosion and rate of sediment outflow from catchments, J. Hydraul. Eng. 131, 9, 755-769, DOI: 10.1061/(ASCE)0733-9429(2005) 131:9(755).

Klaassen, G.J. (1997), FRIMAR: Flooding risks in mountain areas, available at http://www.hrwallingford.co.uk/Mitch/papers/klaassen.pdf.

Krysanova, V., F. Hattermann, and F. Wechsung (2005), Development of the ecohydrological model SWIM for regional impact studies and vulnerability assessment, Hydrol. Process. 19, 3, 763-783, DOI: 10.1002/hyp.5619.

Lajczak, A. (1996), Modelling the long-term course of non-flushed reservoir sedimentation and estimating the life of dams, Earth Surf. Proc. Land. 21, 12, 1091-1107, DOI: 10.1002/(SICI)1096-9837(199612)21:12<1091::AIDESP653>3.0.CO;2-2.

Lenzi, M.A. (2001), Step-pool evolution in the Rio Cordon, northeastern Italy, Earth Surf. Proc. Land. 26, 9, 991-1008, DOI: 10.1002/esp.239.

Lenzi, M.A., and L. Marchi (2000), Suspended sediment load during floods in a small stream of the Dolomites (northeastern Italy), Catena 39, 4, 267-282, DOI: 10.1016/S0341-8162(00)00079-5.

Lenzi, M.A., V. D’Agostino, and P. Billi (1999), Bedload transport in the instrumented catchment of the Rio Cordon. Part I: Analysis of bedload records, conditions and threshold of bedload entrainment, Catena 36, 3, 171-190, DOI: 10.1016/S0341-8162(99)00016-8.

Lenzi, M.A., L. Mao, and F. Comiti (2003), Interannual variation of suspended sediment load and sediment yield in an alpine catchment, Hydrolog. Sci. J. 48, 6, 899-915, DOI: 10.1623/hysj.48.6.899.51425.

Lenzi, M.A., L. Mao, and F. Comiti (2004), Magnitude-frequency analysis of bed load data in an Alpine boulder bed stream, Water Resour. Res. 40, W07201, DOI: 10.1029/2003WR002961.

Lenzi, M.A., L. Mao, and F. Comiti (2006), When does bedload transport begin in steep boulder-bed streams?, Hydrol. Proc. 20, 16, 3517-3533, DOI: 10.1002/hyp.6168.

Lisle, T.E., Y. Cui, G. Parker, J.E. Pizzuto, and A.M. Dodd (2001), The dominance of dispersion in the evolution of bed material waves in gravel-bed rivers, Earth Surf. Proc. Land. 26, 13, 1409-1420, DOI: 10.1002/esp.300.

Madej, M.A., and V. Ozaki (1996), Channel response to sediment wave propagation and movement, Redwood Creek, California, USA, Earth Surf. Proc. Land. 21, 10, 911-927, DOI: 10.1002/(SICI)1096-9837(199610)21:10<911::AIDESP621>3.0.CO;2-1. 
Mandelli, M., L. Longoni, M. Papini, F. Roncoroni, and A. Radice (2009), Modellazione del trasporto di sedimenti sul bacino del Tartano (Valtellina), GEAM 46, 2, 53-64 (in Italian).

Mao, L., and M.A. Lenzi (2007), Sediment mobility and bedload transport conditions in an alpine stream, Hydrol. Process. 21, 14, 1882-1891, DOI: 10.1002/hyp.6372.

Mao, L., G.P. Uyttendaele, A. Iroumé, and M.A. Lenzi (2008), Field based analysis of sediment entrainment in two high gradient streams located in Alpine and Andine environments, Geomorphology 93, 3-4, 368-383, DOI: 10.1016/ j.geomorph.2007.03.008.

Mao, L., M. Cavalli, F. Comiti, L. Marchi, M.A. Lenzi, and M. Arattano (2009), Sediment transfer processes in two Alpine catchments of contrasting morphological settings, J. Hydrol. 364, 1-2, 88-98, DOI: 10.1016/j.jhydrol. 2008.10.021.

Marchi, L., and P.R. Tecca (1996), Magnitudo delle collate detritiche nelle Alpi Orientali Italiane, GEAM 33, 2, 79-86 (in Italian).

Martin, Y. (2003), Evaluation of bed load transport formulae using field evidence from the Vedder River, British Columbia, Geomorphology 53, 1-2, 75-95, DOI: $10.1016 / \mathrm{S} 0169-555 \mathrm{X}(02) 00348-3$.

Meyer-Peter, E., and R. Müller (1948), Formulas for bed-load transport, Proc. 2nd Meeting of IAHR, Stockholm, Sweden.

Milzow, C., P. Molnar, B.W. McArdell, and P. Burlando (2006), Spatial organization in the step-pool structure of a steep mountain stream (Vogelbach, Switzerland), Water Resour. Res. 42, W04418, DOI: 10.1029/2004WR003870.

Montgomery, D.R., and J.M. Buffington (1997), Channel-reach morphology in mountain drainage basins, Bull. Geol. Soc. Am. 109, 5, 596-611, DOI: 10.1130/0016-7606(1997)109<0596:CRMIMD>2.3.CO;2.

Owczarek, P. (2008), Hillslope deposits in gravel-bed rivers and their effects on the evolution of alluvial channel forms: A case study from the Sudetes and Carpathian Mountains, Geomorphology 98, 1-2, 111-125, DOI: 10.1016/ j.geomorph.2007.02.028.

Paola, C., G. Parker, R. Seal, S.K. Sinha, J.B. Southard, and P.R. Wilcock (1992), Downstream fining by selective deposition in a laboratory flume, Science 258, 5089, 1757-1760, DOI: 10.1126/science.258.5089.1757.

Papanicolaou, A.N., A. Bdour, and E. Wicklein (2004), One-dimensional hydrodynamic/sediment transport model applicable to steep mountain streams, J. Hydraul. Res. 42, 4, 357-375, DOI: 10.1080/00221686.2004. 9641204.

Reid, S.C., S.N. Lane, J.M. Berney, and J. Holden (2007), The timing and magnitude of coarse sediment transport events within an upland, temperate gravel-bed river, Geomorphology 83, 1-2, 152-182, DOI: 10.1016/ j.geomorph.2006.06.030. 
Rickenmann, D. (1995), Beurteilung von Murgängen, Schweizer Ingenieur und Architekt 48, 1104-1108 (in German).

Rickenmann, D. (1997), Sediment transport in Swiss torrents, Earth Surf. Proc. Land. 22, 10, 937-951, DOI: 10.1002/(SICI)1096-9837(199710)22:10 $<937:: A I D-E S P 786>3.0 . C O ; 2-R$.

Rickenmann, D. (2001), Comparison of bed load transport in torrents and gravel bed streams, Water Resour. Res. 37, 12, 3295-3305, DOI: 10.1029/2001 WR000319.

Rickenmann, D., and A. Koschni (2010), Sediment loads due to fluvial transport and debris flows during the 2005 flood events in Switzerland, Hydrol. Proc. 24, 8, 993-1007, DOI: 10.1002/hyp.7536.

Rickenmann, D., and M. Zimmermann (1993), The 1987 debris flows in Switzerland: documentation and analysis, Geomorphology 8, 2-3, 175-189, DOI: 10.1016/0169-555X(93)90036-2.

Seal, R., C. Paola, G. Parker, J.B. Southard, and P.R. Wilcock (1997), Experiments on downstream fining of gravel: I. Narrow-channel runs, J. Hydraul. Eng. 123, 10, 874-884, DOI: 10.1061/(ASCE)0733-9429(1997)123:10(874).

Shields, A. (1936), Application of Similarity Principles and Turbulence Research to Bed-Load Movement, Mitteilungen der Preussischen Versuchsanstalt für Wasserbau und Schiffbau, Tech. Hochsch., Berlin, Germany (in German).

Sklar, L.S., J. Fadde, J.G. Venditti, P. Nelson, M.A. Wydzga, Y. Cui, and W.E. Dietrich (2009), Translation and dispersion of sediment pulses in flume experiments simulating gravel augmentation below dams, Water Resour. Res. 45, W08439, DOI: 10.1029/2008WR007346.

Takei, A. (1984), Interdependence of sediment budget between individual torrents and a river-system, Proc. Int. Symp. INTERPRAEVENT, Villach, Austria, Vol. 2, 35-48.

Turowski, J.M., E.M. Yager, A. Badoux, D. Rickenmann, and P. Molnar (2009), The impact of exceptional events on erosion, bedload transport and channel stability in a step-pool channel, Earth Surf. Proc. Land. 34, 12, 1661-1673, DOI: 10.1002 /esp.1855.

Turowski, J.M., D. Rickenmann, and S.J. Dadson (2010), The partitioning of the total sediment load of a river into suspended load and bedload: A review of empirical data, Sedimentology 57, 4, 1126-1146, DOI: 10.1111/j.13653091.2009.01140.x.

Van Rompaey, A., P. Bazzoffi, R.J.A. Jones, and L. Montanarella (2005), Modeling sediment yields in Italian catchments, Geomorphology 65, 1-2, 157-169, DOI: 10.1016/j.geomorph.2004.08.006.

Wang, G., P. Hapuarachchi, H. Ishidaira, A.S. Kiem, and K. Takeuchi (2009), Estimation of soil erosion and sediment yield during individual rainstorms at catchment scale, Water Resour. Manag. 23, 8, 1447-1465, DOI: 10.1007/ s11269-008-9335-8. 
Warren, S.D., H. Mitasova, M.G. Hohmann, S. Landsberger, F.Y. Iskander, T.S. Ruzycki, and G.M. Senseman (2005), Validation of a 3-D enhancement of the Universal Soil Loss Equation for prediction of soil erosion and sediment deposition, Catena 64, 2-3, 281-296, DOI: 10.1016/j.catena.2005.08.010.

Wilcock, P.R. (1998), Two-fraction model of initial sediment motion in gravel-bed rivers, Science 280, 5362, 410-412, DOI: 10.1126/science.280.5362.410.

Wilcox, A.C., E.E. Wohl, F. Comiti, and L. Mao (2011), Hydraulics, morphology, and energy dissipation in an alpine step-pool channel, Water Resour. Res. 47, W07514, DOI: 10.1029/2010WR010192.

Williams, J.R., and H.D. Berndt (1975), Sediment yield prediction with universal equation using runoff energy factor. In: Present and Prospective Technology for Predicting Sediment Yield and Sources, USDA, ARS-S-40, 244252.

Wright, S.A., D.J. Topping, D.M. Rubin, and T.S. Melis (2010), An approach for modeling sediment budgets in supply-limited rivers, Water Resour. Res. 46, W10538, DOI: 10.1029/2009WR008600.

Received 11 April 2011

Received in revised form 15 September 2011

Accepted 19 September 2011 